\title{
Health Resources and Services Administration
}

National Cancer Institute

\section{Source}

National Cancer Institute. Health Resources and Services Administration. NCI Thesaurus. Code $C 39417$.

The Health Resources and Services Administration (HRSA) is an Access Agency of the U.S. Department of Health and Human Services, charged with improving and expanding access to quality health care for low income, uninsured, isolated, vulnerable and special needs populations and meeting their unique health care needs. Provides funds for scientific projects and public health programs. 